\title{
Strategic Procurement and Financial Performance of Iranian Manufacturing Companies
}

\author{
Maryam Sobhani ${ }^{1}$, C. A. Malarvizhi ${ }^{2}$, Abdullah Al- Mamun ${ }^{3} \&$ Sreenivasan Jeyashree ${ }^{2}$ \\ ${ }^{1}$ Graduate School of Management, Multimedia University, Malaysia \\ ${ }^{2}$ Faculty of Management, Multimedia University, Malaysia \\ ${ }^{3}$ Faculty of Entrepreneurship and Business, Universiti Malaysia Kelantan, Malaysia \\ Correspondence: Abdullah Al- Mamun, Faculty of Entrepreneurship and Business, Universiti Malaysia Kelantan, \\ Malaysia. Tel: 60-9-771-7251.E-mail: abdullah.a@umk.edu.my; mamun7793@gmail.com
}

Received: July 29, 2013 Accepted: October 7, 2013 Online Published: December 31, 2013

doi:10.5539/ass.v10n1p250 URL: http://dx.doi.org/10.5539/ass.v10n1p250

\begin{abstract}
Procurement has turned into the strategy for cutting cost and improving quality in order to increase the efficiency of the procurement function and reduce production costs. The objective of this study is to scrutinize the interrelation between the level of strategic procurement and financial performance of manufacturing companies in Iran. A cross-sectional explanatory study was designed to identify Iranian manufacturing company's procurement management practices and performance outcome. Findings of this study noted a positive relationship between the strategic procurement and financial performance of the companies. For developing strategic procurement, firms should therefore improve the skills in their purchasing professionals, tally the strategic procurement with overall business strategy with long-term plans, select the potential and key suppliers, and create a good relationship with them. These factors could affect a firm's financial performance and increase profit.
\end{abstract}

Keywords: procurement, financial performance, cost reduction, manufacturing companies

\section{Introduction}

In today's competitive business environment, many companies are trying to find new ways to achieve a competitive advantage. Many changes have happened to the view points of companies about the function of purchasing. Purchasing has commenced to play a more significant role in the strategy of the firm during the past few years. The recent evolvement of purchasing expanded from "buying" to "procurement" and then to "supply management" has found a similar growing importance as well as supply chain management. The strategic role of purchasing as an important contributor to the strategic success of the company is receiving enhanced attention. The movement away from the philosophies of mass production has brought new ways to the traditionally operational task of purchasing and this has created the concept of purchasing as a part of the strategic function of supply chain management which should be aligned to the overall corporate strategy. According to Ferguson, Hartley, and Pierce (1996) the level of involvement of the procurement department in the corporate strategic planning process has increased through the 1970s and 1980s. Carr and Smeltzer (1997) stated that in the 1970s and early 1980s, purchasing took a supportive function. The literature indicates the movement toward integrating purchasing into the company's strategic planning process implemented during the 1990s (Cannon, 1968). Recently, the notion of procurement has been discussed in many studies. The popularity of that topic could have emanated from many drivers, including trends in global sourcing, highlighting on time to market, product quality based competition, customer uncertainty and the requirement to develop bottom-line costs (Kalakota \& Robinson, 2001). Nowadays, procurement has an important strategic role in the value chain and is also a major driver in the extended supply chain.

Procurement is an overriding work for businesses to master due to several factors such as increased global scope of operations, increased usage of outsourcing, and the buyers' increased dependence on suppliers' capabilities (Knudsen, 2003). As a result, the transformation of procurement processes has occurred from the lowly, back-end processes into a strategic resource during the last decade. Kalakota and Robinson (2001) mentioned that the single largest expense item for any given business is basically represented by the purchase of goods and 
services. It is approximated that for each dollar a company achieves from the sale of a product it expends over fifty percent of this one dollar (i.e. from $\$ 0.50$ to $\$ 0.60$ ) on goods and services. Leenders et al. (2006) declared that in almost all manufacturing organisations, the procurement area is the largest single category of spend, ranging from fifty to eighty five percent of revenue. Therefore, the function of procurement is very important for companies especially manufacturing organisations because purchasing materials and services cover the highest proportion of the cost of goods sold. Numerous research has verified that the overall cost of a business is substantially affected by even small savings on purchasing related expenditure (Weele, 2000). Many organisations in order to increase profitability, expect the purchasing department to minimize cost against budgetary norms.

Investigation in procurement is generally conducted at an operational and strategic level. As such make-buy decisions, tuning the procurement function at the operational level creates a lot of financial and non-financial benefits for companies. However, sustaining competitive advantage for an enterprise entails a strategic attention to all a company's departments. Hence, formulation of suitable strategies for procurement process could help the company to improve its strategic position. Adopting different procurement strategies in terms of suitability and orientation with overall company's strategies could generate different outcomes. This strategic viewpoint of procurement has not gained suitable degree of attention as well as operational insight. The main focus of this study is to scrutinize the interrelation between the level of strategic procurement and financial performance of manufacturing companies. Besides, the significant level of the three determinants of strategic procurement (strategic alignment, purchasing skills, and supplier involvement) which were declared by other scholars, will be probed. Findings of this study contribute to the strategic procurement to improve the financial performance. The managers can develop procurement functions by improving the purchasing skills of their employees, establishing good relationship with key suppliers, having a long-term contract with the limited suppliers, and also orienting the strategies of procurement and overall corporate strategy. Leaders, procurement managers and purchasing experts could exploit the outcome of the study to elevate the financial position of a company by evolving the procurement function into the strategic. If a company to be more strategic in procurement, the impact of purchasing function could be more on the financial performance of the firm.

\section{Literature Review}

Porter (1998) described the value chain as a template that firms use to understand their cost position and to identify the multiple means that might be used to facilitate implementation of a chosen business-level strategy. A firm's value chain is divided into primary and support activities. One of the most important activities in the value chain is procurement. Segev (1998) defined procurement as "all activities involved in obtaining goods and services and managing their inflow into an organisation". Segev (1998) in his statement, emphasized the managing of materials and inflow into the firm. Leaonard (2000) referred to the operational activities of the procurement.

Organisations are able to obtain a multitude of benefits by well-managed procurement business functions. The profit and competitiveness of an enterprise is highly reliant on how procurement is implemented within the firm. The purchasing of goods and services of a firm account for $50 \%$ to $70 \%$ of total costs (McGinnis \& McCarty, 1998). It has direct impact on profit because procurement represents the largest proportion of expenses in the firm. There is also an indirect impact on the profit due to the substantial part of the internal costs affecting what occurs in the interface between the firm and its suppliers (Gadde \& Hakansson, 1998). Gadde \& Håkansson (1998) stated that "purchasing costs often stand for between 40 and 60 percent of a company's turnover". The development of the procurement function has the ability to influence corporate profitability. The procurement function has changed from the passive, reactive clerical viewpoint of the 70's to a strategic proactive function contributing, as much as other business functions, to build a desirable competitive advantages (Versendaal et al. 2005). Procurement has evolved from a clerical buying task into a strategic business function that contributes to the competitive position of companies (Ellram \& Carr, 1994; Carter \& Narasimhan, 1996).

According to Gadde \& Hakansson (1998), some reasons show the importance of purchasing and why purchasing consists of a huge part of the turnover. Firstly purchasing has increasingly become more involved in larger proportions of the company's total activity. That is because of the fact that the purchasing department's capability and competency have great consequences for the efficiency of the company. Purchasing has an important role in the company's profitability. A second reason why purchasing has become more important is that purchases affect the result directly. Each dollar less spent on purchasing is one dollar extra added to the profit margin. The third reason for the importance of purchasing is the insight that benefits can be created by deep and long-term relationships with a supplier. 
The effective purchasing function should be able to access the information of supplier industry such as supplier markets, events, and technology that are crucial to a business. These potential benefits deal with flow of material, flow of information and cooperation in technical development. The next reason for the importance of purchasing is the increased complication that purchasing involves. By developing society, the differentiation and the specialized units, procurement process becomes more complicated. The increased specialization has led to products which are more complex and has a more complicated purchasing process. Many companies purchase some material from the other countries. Therefore, international procurement has also expanded which has led to a number of new problems such as: the accessibility to suppliers, handling currencies and different legislations. Since organisations have turned their focus to lowering costs and increasing efficiency, the procurement function has gained an increasingly significance.

In the past decades, procurement had a passive role in the business organisation and it has involved as day-to-day operational activities. Many strategists supported procurement as a strategy and they believed that procurement had been more administrative than a strategic function many years ago. Nowadays, it has become involved in both tactical and strategic decisions in successful companies. During the last twenty years, strategic management of procurement is a topic which is often discussed and has had more attention. Procurement plays a strategic role in a company's profitability and improves shareholder values.

Strategic procurement is defined as the process of planning, evaluating, implementing, and controlling highly important and routine sourcing decisions (Carr \& Smeltzer, 1997). Thus, a strategic procurement function can help the company to increase its ability to be competitive. According to Carter and Narasimhan (1996), if a company followed five fundamental principles, its effort could be successful at procurement strategy development: 1) the alignment between firm-level strategies and goals of purchasing management, 2) effectiveness of human resource management, 3) closely linking with key suppliers, 4) purchasing functions must integrate with other manufacturing functions, 5) generate the suitable environment within procurement.

The procurement function was seen as a strategic resource for reaching high quality levels, fast delivery, and cost savings. A well-known statement of the objectives of procurement is: to acquire the right quality of material, at the right time, in the right quantity, from the right source, at the right price. The firms need to strategically purchase the materials and services that will increase their ability to meet their customer's needs and market share. The procurement function is not limited to purchase raw materials, parts and services, however, it should handle much broader functions of supply.

In strategic supply, the key question is how can supply and the supply chain contribute effectively to organisational objectives and strategy? The accompanying question is how can the organisational objectives and strategy properly reflect the contribution and opportunities offered in the supply chain? A number of previous research studies have focused on the procurement strategies. The 1980s were a period of shifting attitudes towards the role of purchasing in corporate strategy (Ellram \& Carr, as cited in Virolainen, 1998). Previous research showed that the procurement could work to become known as a more significant contributor to the firm's success. Purchasing has gained an important strategic role with enhancing trend and evolving from a vague buying function into a strategic business partner by growing importance of supply-chain management (Ellram \& Carr, 1994; Cooper \& Ellram, 1993). Cavinato (1999) stated how strategic procurement actively contributes in corporate planning process. Procurement strategy facilitates organisation-environment alignment to enjoy mutual benefits (Carter \& Narasimhan, 1996), and promotes cross-functional integration among supply chain activities, among other things. Therefore, purchasing plays a key interchange role between external suppliers and internal organisational customers in creating and delivering value to external customers (Novack \& Simco, 1991).

When firms possess the skills and knowledge necessary to engage in gathering and processing information, they have an important means of competing with other firms (Spender, 1996). The firm's strategies play an important role in construction of purchasing function. If purchasing has an integrative role in the firm's strategic planning process, then the purchasing function can be characterized as a strategic function (Ammer, 1989; Reck \& Long, 1988). Previous studies declared that procurement and supply management can have an impact on firms' financial performance (Ellram \& Liu, 2002; Singhal \& Hendricks, 2002). In many companies, strategic procurement is now seen as vital to competitiveness (Carr \& Pearson, 2002). They found that it has a positive effect on the firm's financial performance. Procurement performance has mostly been measured using accounting measures such as ratio of purchasing operation expense to total purchase dollars spent, and ratio of purchasing operation expense to sales revenue (Seaman, 1992). Supply chain is recognized as a strategy to improve the businesses performance. Supply chain activities affect all elements of a company's or organisation's financial performance, including operation cost, revenue growth, and asset management. 


\section{Research Methodology}

This study is an explanatory research to test the hypothesis regarding the relationship between strategic procurement and a firm's financial performance. The type of investigation in this research is causal. A survey was used to gather data pertaining to the research questions and hypotheses. Since this study is an explanatory research to test the hypothesis, researcher interference in this type of research is low. Regarding the fact that the cause and effect relationship is invariably conducted in non-contrived settings; the study setting of this research is classified into the field study. The unit of analysis is the manufacturing companies in Tehran. Moreover, since the data are gathered once, this study can be classified as cross-sectional studies.

The operationalized constructs of strategic procurement concept (strategic alignment, purchasing skills, and supplier involvement) and also the financial performance concept (ROA and profit as a percentage of sales) are measured by administrating a questionnaire on the basis of the 7-point Likert scale questions. Therefore, the result of mentioned questionnaire would be interval scale which can be tested under many statistical analyses.

A questionnaire was designed in 26 questions which are divided into four parts. The first part is the alignment between strategic procurement and company's strategy, the second part is about the professional skills, the third part is the supplier's involvement in strategic procurement and the last part is the questions about firm's financial performance. A seven-point Likert scale with end points of "strongly disagree" and "strongly agree" was used to measure the items. The firm's financial performance were measured using a seven-point Likert scale with endpoints of "decreased significantly" and "increased significantly". This allowed executives to rank their agreement to a statement relative to positive and negative endpoints of a seven-point Likert scale.

The survey was operated in mailing. The initial mailing comprised an individual cover letter explaining the purpose of the study and a survey questionnaire were sent to all members in the selected sample. The purchasing directors and purchasing managers were targeted because they are most familiar with their company's procurement management practices and performance outcome. A total of 175 questionnaires were mailed to Iranian manufacturing companies spanning from small to large sized enterprises. The response rate was $48 \%$ due to the fact that only 84 out of 175 firms responded.

\section{Summary of Findings}

\subsection{Demographic}

The common characteristics of responding companies were noted addressing the number of employees and total sales per year. As noted in Table 1 the companies' sizes are divided into small, medium and large size in manufacturing industry (Table 4). The small size companies represented with 43 responses $(51.2$ percent), medium size companies with 35 responses (41.7 percent), and large size companies with 6 responses (7.1 percent). Table 1 illustrated the sales of 46 firms were up to one million dollars ( 54.8 percent) and the sales of 38 firms were one to ten million dollars (45.2 percent).

Table 1. Size of companies and sales

\begin{tabular}{lcclcc}
\hline Size & Frequency & Percent & Sales & Frequency & Percent \\
\hline 1-50 -Small Size & 43 & 51.2 & Up to 1 Million USD & 46 & 54.8 \\
50-250- Medium Size & 35 & 41.7 & 1-10 Million USD & 38 & 45.2 \\
250-1000-Large Size & 6 & 7.1 & Total & 84 & 100.0 \\
Total & 84 & 100.0 & & & \\
\hline
\end{tabular}

\subsection{Exploratory Factor Analysis (EFA) and Reliability Analysis}

This study intended to investigate the relationship between strategic procurement and financial performance of the manufacturing companies. To explore the relationship, an instrument in the form of a questionnaire based on 7-point Likert scale was developed. Exploratory factor analysis was carried out to uncover the underlying structure of variables for each construct. This means that the questions about each construct were collected from different literature, it should be investigated how many sub-constructs are there in each construct structure.

Kaiser-Meyer-Olkin (KMO) statistics as a measure of sampling adequacy on the basis of correlation and partial correlation predicts if data are likely to factor well. According to Table 2, KMO for Skill and Supplier Involvement construct is $0.832,0.675$ and 0.799 respectively, which are higher than 0.6 whereby it is possible to 
proceed with factor analysis. Financial Performance construct has only two variables, therefore the exploratory factor analysis is not applicable.

Table 2. EFA and reliability analysis

\begin{tabular}{lccc}
\hline Variables & Components & KMO & Cronbach's Alpha \\
\hline Skills & 13 & 0.675 & 0.790 \\
Supplier Involvement & 5 & 0.799 & 0.772 \\
\hline
\end{tabular}

The reliability of a measure is an indication of the stability and consistency with which the instrument measures the concept and helps to assess the goodness of a measure. In this study, Cronbach Alpha which is a perfectly adequate index of interitem consistency reliability is selected. The Cronbach Alpha for Skill and Supplier Involvement construct is $0.790,0.790$ and 0.772 respectively, which are higher than 0.6 . The instruments used to measure independent variables are therefore considered as reliable.

\subsection{Analysis of Structural Model}

In the structural portion of the model, each path with a single headed arrow is estimated by a structural equation. Primarily, the amount of each construct was calculated based on the arithmetic mean of its variables. The outcome of analysis on the structural model is illustrated in Figure 1 and summarised in Table 3.

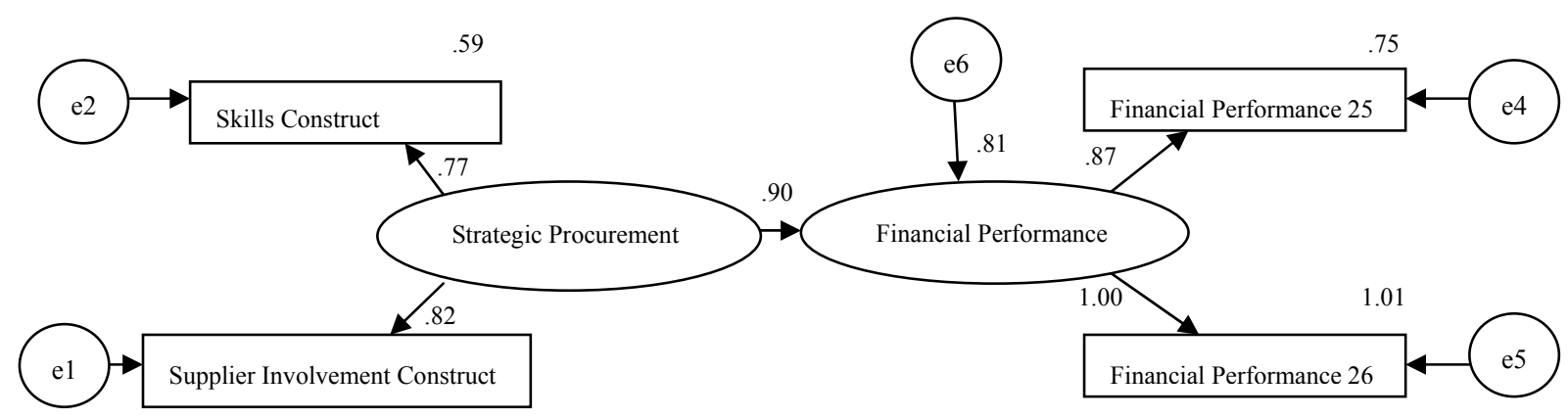

.67

Figure 1. Structural model

Jaccard and Wan (1996) recommend that at least three fit statistics should be within the range to accept the fitness of the model. Table 3 indicates that all of fit statistics support the model's goodness of fit.

Table 3. Goodness of fit statistics for supplier involvement construct

\begin{tabular}{cccc}
\hline Goodness of Fit Statistics & Value & Acceptable Limit & Goodness of Fit \\
\hline CMIN/DF & 0.651 & $\leq 2$ & Yes \\
CFI & 1.000 & $\geq 0.9$ & Yes \\
TLI & 1.009 & $\geq 0.9$ & Yes \\
IFI & 1.001 & $\geq 0.9$ & Yes \\
RFI & 0.984 & $\geq 0.9$ & Yes \\
NFI & 0.997 & $\geq 0.9$ & Yes \\
RMSEA & 0.000 & $\leq 0.08$ & Yes \\
\hline
\end{tabular}

According to Table 4 , the $p$ - value $(<0.01)$ of the test in regard with the relationship between strategic procurement (independent variable) and financial performance (dependent variable) is lower than $\alpha=0.05$ and also the Critical Ratio $(\mathrm{CR}=6.87)$ is higher than 1.96 , the null hypothesis is rejected and it could be concluded that there is a significant relationship between strategic procurement and financial performance of manufacturing companies $(\alpha=0.05)$. 
Table 4. Regression weights of structural model

\begin{tabular}{|c|c|c|c|c|c|}
\hline & & Estimate & S.E. & C.R. & $\mathrm{P}$ \\
\hline Financial Performance & $<---$ Strategic Procurement & 1.670 & 0.243 & 6.872 & $* * * 1$ \\
\hline Supplier Involvement Construct & $<---\quad$ Strategic Procurement & 1.000 & & & \\
\hline Skills Construct & $<---$ Strategic Procurement & 0.605 & 0.080 & 7.525 & $* * *$ \\
\hline Financial Performance_25 & $<---$ Financial Performance & 1.000 & & & \\
\hline Financial Performance_26 & $<---$ Financial Performance & 1.208 & 0.095 & 12.772 & $* * *$ \\
\hline
\end{tabular}

\section{Conclusion and Recommendation}

Every organisation has aims to survive and be profitable by achieving some sort of competitive advantage and make it sustainable. Hence, studies have been carried out to scrutinise the sources of competitive advantage. Regarding the resource-base view, the enterprise tries to fully exploit its resources in the efficient and effective way to increase its financial performance followed by creating a competitive advantage. This approach caused the procurement to gain attention as one of the most overriding resources of companies. That is because of the fact that in almost all manufacturing organisations, the procurement area is the largest single category of spend, ranging from fifty to eighty five percent of revenue. Procurement has evolved from a clerical buying function into a strategic business function that contributes to the competitive position of companies. Effective formulation and efficient implementation of suitable strategies could help the company to achieve success in term of financial performance. Procurement strategy is evolved from the concept of strategic management. When the purchasing function is familiar with the company's strategic objectives, it is able to commence the process of developing procurement strategies. Therefore, the procurement strategy will be in congruence with the overall business strategy.

This study substantiated that there is a positive relationship between the strategic procurement and financial performance of the companies. Since the strategic procurement concept was investigated through purchasing skills and supplier involvement constructs, the main conclusion of this study could summarised into two points. First, by improving the skills of procurement personnel, an organisation could achieve a better financial performance following by getting strategic in procurement. Second, engaging the key suppliers from the design process to cooperatively solving the supply chain predicaments could diminish the wastes of an organisation and subsequently increase its financial performance. The managers should therefore focus on attempts to find out corporate and/or business strategy and understand it so that they can align the strategic procurement with corporate strategy, and demonstrate how procurement management can reply to organizational objectives and goals. Organisations may set up internal classes to teach the essential skills to their employees or may find it necessary to recruit procurement professionals with these skills. The managers can select the key suppliers; establish close relationships with suppliers to make certain efficient and high quality delivery of materials.

As for the future studies, it is recommended to repeat the current study using a complex and more precise instruments for measuring the strategic procurement and financial performance concepts. Investigating the existence of probable mediators or moderators in the relationship between strategic procurement and financial performance should be included in the future studies. Compare the implications of this study with outcome of investigation of the same relationship in the service sector, and to increase the sample size to enhance the precision of findings.

\section{References}

Ammer, D. (1989). Top Management's View of the Purchasing Function. Journal of Purchasing and Materials Management, 25(3), 16-21.

Cannon, J. T. (1968). Business strategy and policy. Harcourt, Brace and World, San Diego.

Carr, A. S., \& Smeltzer, L. R. (1997). An empirically based operational definition of strategic purchasing. European Journal of Purchasing and Supply Management, 3(4), 199-207. http://dx.doi.org/10.1016/S0969-7012(97)00014-2

Carter, J. R., \& Narasimhan, R. (1996). Is purchasing really strategic? International Journal of Purchasing and Materials Management, 32(1), 20-28. http://dx.doi.org/10.1111/j.1745-493X.1996.tb00216.x 
Ellram, L. M., \& Pearson, J. N. (1993). The Role of the purchasing function: Toward team participation. International Journal of Purchasing and Materials Management, 29(3), 3-9.

Ellram, L. M., \& Liu, B. (2002). The financial impact of supply management. Supply Chain Management Review, 6(6), 30-36.

Ferguson, W. C., Hartley, M. F., Turner, G. B., \& Pierce, E. M. (1996). Purchasing's role in corporate strategic planning. International Journal of Physical Distribution and Logistics Management, 26, 51-62. http://dx.doi.org/10.1108/09600039610116512

Gadde, L. E., \& Hakansson, H. (2001). Supply chain Network Strategies. John Wiley \& Sons, Chichester.

Kalakota, R., \& Robinson, M. (2001). E-Business 2.0: Roadmap for Success. Boston: Addison-Wesley.

Knudsen, D. (2003). Improving procurement performance with E-business mechanisms. Lund University. Lund, Sweden.

Leenders, M. R., Johnson, P. F., Flynn, A. E., \& Fearon, H. E. (2006). Purchasing and supply Management (13th ed.). Chicago: McGraw-Hill.

McGinnis, F., \& McCarty, L. (1998). Strategic account management in the new procurement environment. Supply Chain Management, 3(1), 5-12. http://dx.doi.org/10.1108/13598549810200843

Novack, R. A., \& Simco, S. W. (1991). The industrial procurement process: A supply chain perspective. Journal of Business Logistics, 12(1), 145-167.

Porter, M. E. (1988). Clusters and the New Economics of Competition. Harvard Business Review, 77-90.

Reck, R. F., \& Long, B. (1988). Purchasing, a competitive weapon. Journal of Purchasing and Materials Management, 24(3), 1-12.

Spender, J. C., \& Grinyer, P. H. (1996). Organizational renewal: Deinstitutionalization and loosely coupled systems. International Studies of management and Organization, 26, 17-40.

Versendaal, J., Beukers, M., \& Batenburg, R. (2005). Business Alignment in the Procurement. Domain. Institute of information and computing sciences. Utrecht University.

Weele, A. J. (2000). Purchasing and supply chain management: Analysis, planning and practice. Thomsom Learning, London.

\section{Copyrights}

Copyright for this article is retained by the author(s), with first publication rights granted to the journal.

This is an open-access article distributed under the terms and conditions of the Creative Commons Attribution license (http://creativecommons.org/licenses/by/3.0/). 